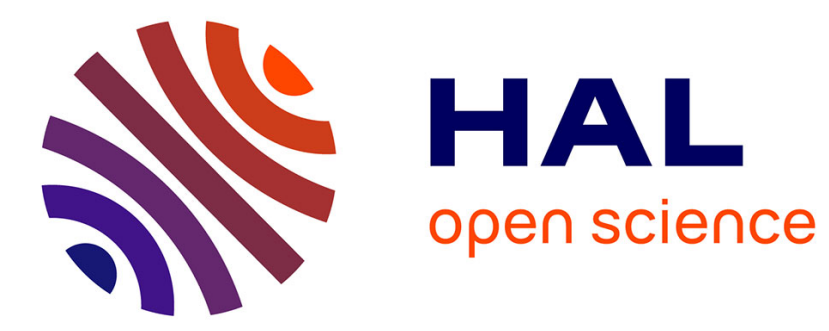

\title{
Experimental Tool of woven Reinforcement Forming
} Samir Allaoui, Jean Launay, D. Soulat, S. Chatel

\section{To cite this version:}

Samir Allaoui, Jean Launay, D. Soulat, S. Chatel. Experimental Tool of woven Reinforcement Forming. International Journal of Material Forming, 2008, 1 (1), pp.815-818. hal-00636982

\section{HAL Id: hal-00636982 https://hal.science/hal-00636982}

Submitted on 10 Apr 2018

HAL is a multi-disciplinary open access archive for the deposit and dissemination of scientific research documents, whether they are published or not. The documents may come from teaching and research institutions in France or abroad, or from public or private research centers.
L'archive ouverte pluridisciplinaire HAL, est destinée au dépôt et à la diffusion de documents scientifiques de niveau recherche, publiés ou non, émanant des établissements d'enseignement et de recherche français ou étrangers, des laboratoires publics ou privés. 


\title{
Experimental tool of woven reinforcement forming
}

\author{
S. Allaoui ${ }^{1}$, J. Launay ${ }^{1}$, D. Soulat ${ }^{1}$, S. Chatel $^{2}$ \\ ${ }^{1}$ PRISME/LMSP - Polytech'Orléans, 8Rue léonard de Vinci, 45072 Orléans cedex2, France \\ e-mail:samir.allaoui@univ-orleans.fr; \\ jean.launay@univ-orleans.fr \\ damien.soulat@univ-orleans.fr;
}

${ }^{2}$ EADS France, Mechanical Modelling Research Team, 12 rue Pasteur, BP76, 92152 Suresnes cedex, France e-mail:sylvain.chatel@eads.net

\begin{abstract}
An experimental device of dry preforms stamping was designed and carried out for the first stage of the RTM process. This tool was developed to test the feasibility to obtain specific double curved shape constituted with dry fabric reinforcement. Optical strain measurement can quantify defects on the composite piece. It is just enough to change the desired punch-die set of the preform. This tool could be used to validate numerical simulation of the process.
\end{abstract}

Keywords: Fabric Forming, RTM process, experimental tool, fabric behaviour

\section{INTRODUCTION}

The use of fiber fabrics in transportation industries is increasing because it gives the possibility to reach complex shapes, for a lighter final product with the R.T.M. process. This process consists of a drawing operation of the fabric before a resin is injected. [1]. Aeronautical industries interrogation is on the feasibility to obtain with this process one 3D very complex double-curved shape (figure1) for thick piece constituted by several ply of fabric and without defects.

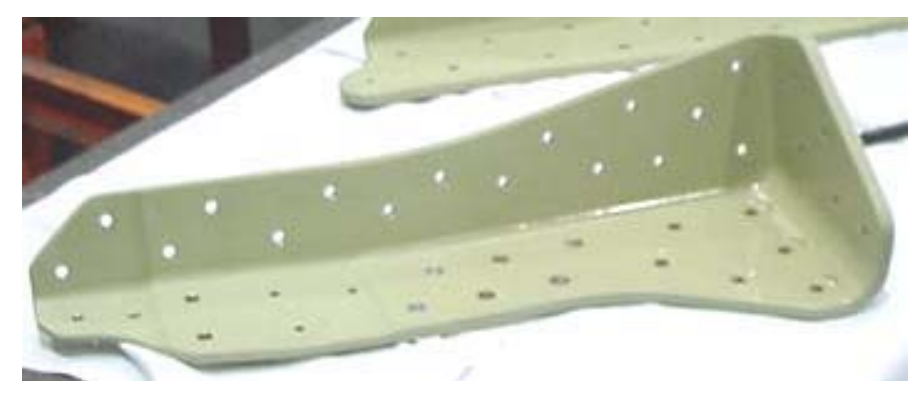

Fig. 1 Aeronautical application

The aim of this paper is on the development of an experimental tool for the first stage of this RTM process, in collaboration with the EADS Company. This tool must permit to envisage the feasibility of a process without defect for thick fabric but also to know the directions of the reinforcements after shaping. These directions condition strongly the mechanical behaviour of the final textile composite structure. In addition, the angles between warp and weft yarns influence the permeability of the reinforcement and thus the filling of the resin in the case of a liquid moulding process [2, 3]. For another point of view this tool will permit to validate numerical simulation of this shaping stage realized by LAMCOS Laboratory. These numerical simulations $[4,5]$, by mechanical analysis of the fabric deformation takes into account the specific mechanical behaviour of the fabric used and especially loads (for example on the blank-holder) which mainly influence the result and the quality of the piece obtained. Consequently this experimental tool is instrumented by systems for strain measurement in yarns, and we choose by optical method, and second to measure parameters process, like pressure or punch velocity.

\section{PRESENTATION OF THE TOOL}

An experimental tool was developed in order to follow the behaviour of dry fabric during the first stage of RTM process.

\subsection{Process parameters instrumentation}

This forming testing machine is composed of a electric cylinder. Different sets of die-punch can be assembled on this tool. Figure 2 shows the different punch associated of these shapes. These shapes were 
considered one because they permit to obtain double-curved shape. On the other hand, on each face, edge, or angular point of these shapes, in function of the initial orientation of yarn, the fabric deformability, and consequently the defaults of forming could be different A blank holder system, control by several pneumatic cylinder is present to tighten at different places of the fabric tested. Some thickness, or plies number of fabric could be tested.

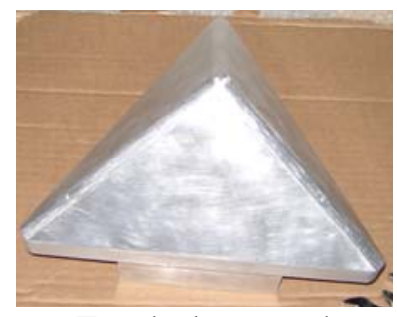

Tetrahedron punch

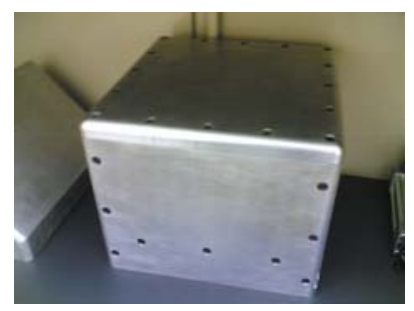

Square punch

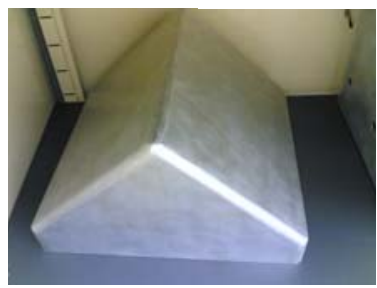

Prism punch

Fig.2 Punches geometry.

In addition various devices were added on this tool. One of them makes it possible to apply an initial tension along yarns of the fabric before this forming step. This device is necessary for very thick fabrics or for several plies considered. Naturally it's possible to measure all parameters which could affect on the process and consequently on the shape obtained, like stroke or load of the punch, blank holder pressure, orientation of the punch, initial tension ...

\subsection{Optical strain measurements}

Optical strain measurements are made simultaneously with two numerical cameras at macro-scale (pictures of the whole shape) and at mesoscale on some few woven cells or at microscale within a yarn. They permit measurement independent of the tool in fact to understand the internal behaviour of the fabric during shaping. The mechanical behaviour which results is complex and specific considering the possibilities of relative movements between yarns. The strain fields are computed using which used marks tracking technique [6, 7] from the displacements of points marked on fabrics. The macroscopic measures permit to compute the shape obtained for the each punch used and during all the process, which could be compared with the shape computed by numerical simulation. Position of the yarn during the process is another important parameter for the simulation in fact to apply the mechanical law behaviour in tension along their direction (warp and weft). During shaping without resin, the principal deformation mode of woven fabrics [8] is the plane shear and could be estimated by measurement of angle between yarns, during the process. When this angle is too large, shear stiffness become significant and it can involve formation of wrinkles [9]. All these quantities permit to quantify defects during this first stage of the RTM process.

\section{EXPERIMENTAL RESULTS}

The tests presented in this paper are carried out on a composite woven reinforcement used in aeronautics. It is denoted $\mathrm{G} 1151^{\circledR}$ fabric and constituted (figure 3) by an interlock weaving links two carbon plies $\left(630 \mathrm{~g} / \mathrm{m}^{2}\right)$.

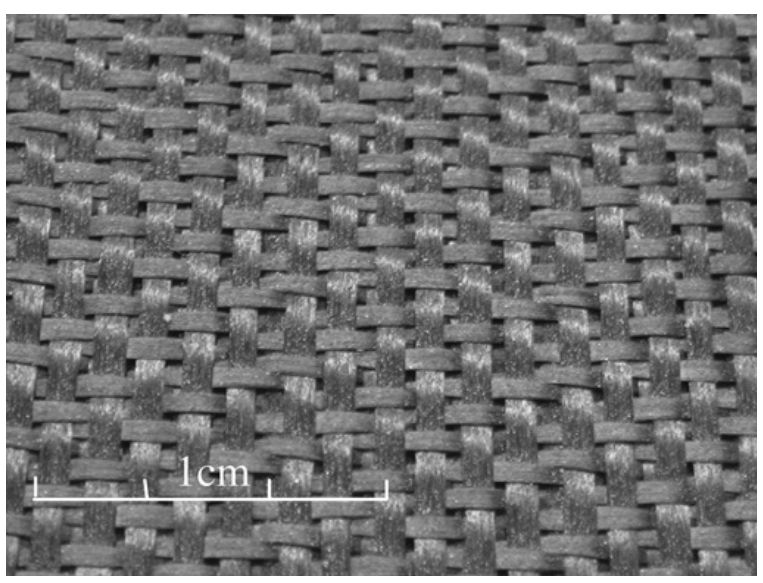

Fig. 3 Woven carbon reinforcement $\left(\mathrm{G} 1151^{\circledR}\right)$.

\subsection{Global preform analysis.}

When the forming test is finished, the fabric preform is removed from the tools and fixed with an epoxy resin spray. On figure 4 a, we present for square punch used, the preform obtained for one ply of the carbon reinforcement considered. In good adequation with the punch shape, the preform is symmetrical. We can observe that the reinforcement is well-stretched; on faces, edges or corner of this shape no defaults like tears appear. We can conclude that blank holder pressure is well-chosen in function of the punch's stroke.

The deformability of the fabric is possible by 
rotation between yarns, and we can notice (figure 4.b), for this shape, locally (corner, edges) that this rotation could become very important. Consequently on these edges, for example, it will be necessary to compute exactly the angle in fact to estimate the shear stiffness in adequation with the shear behaviour of this fabric [9].
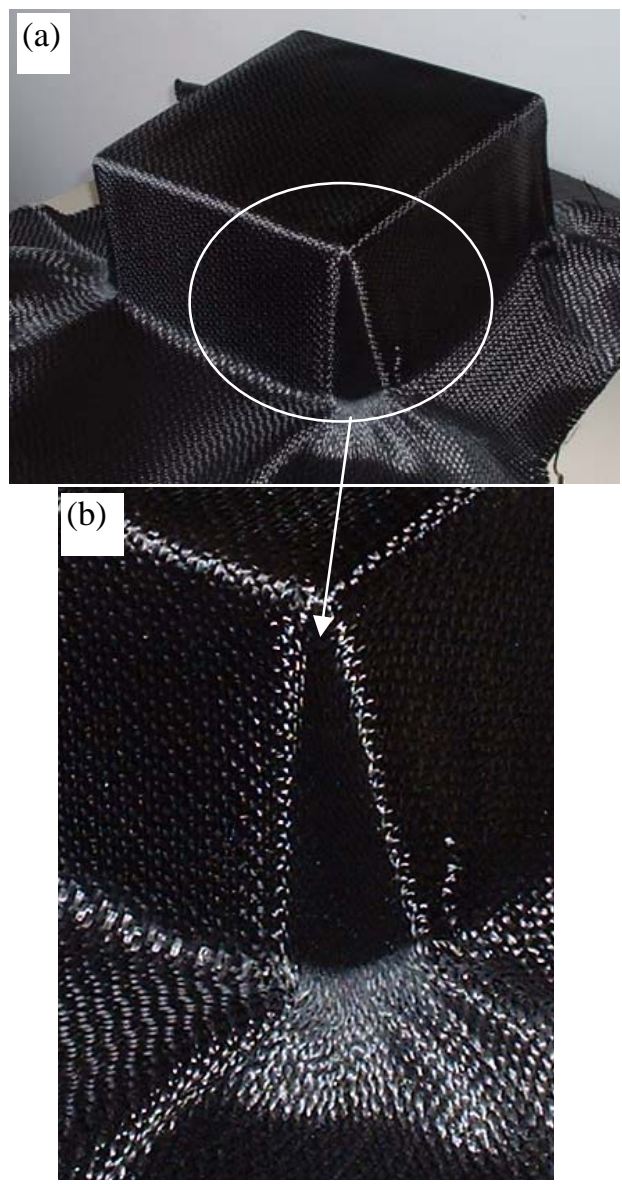

Fig. 4 (a) Global preform obtained. (b) Local shear strain on edge.

\subsection{Optical measurement analyses}

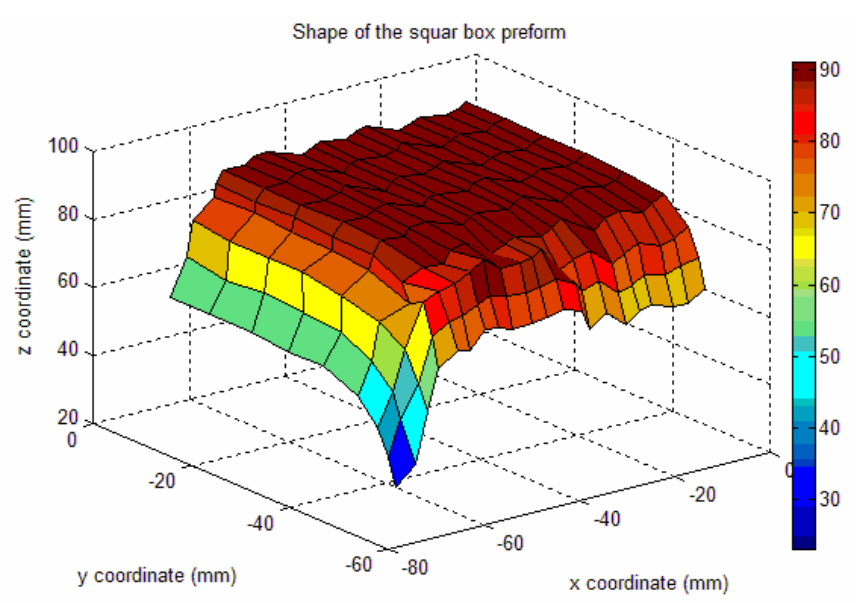

Fig.5 Shape of the square box preform after stamping
With the software of image processing it makes it possible to obtain the instantaneous position of each point marked on fabric. These positions are obtained with the three space co-ordinates. Thus, the post processing enables us to reconstruct the $3 \mathrm{D}$ geometry of the preform (Fig. 5).

The software also gives displacements, and could compute plane component of strain for the fabric. Knowing the instantaneous positions, the shear angles between yarns can thus be computed. Indeed, the local behaviour of fibres can be studied for the same test by considering only the markers along on these fibres. Figure 6 shows an example of the evolution of position of three fibres between the initial and final position. The area considered, is at the top of the face. We noted that the evolution of the position of a fibre is more important near to the corner of the shape.

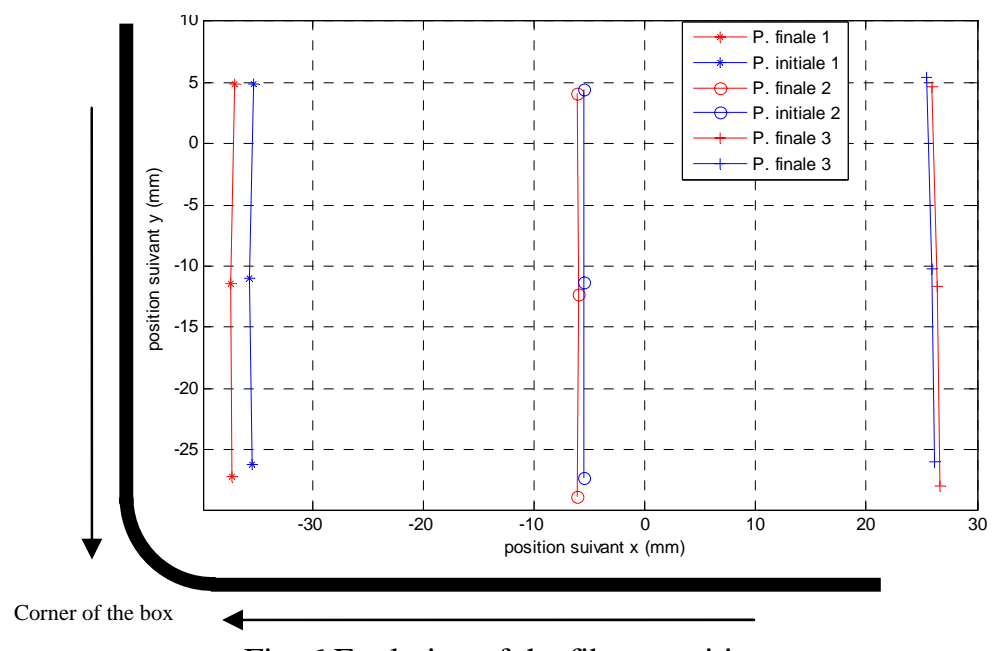

Fig. 6 Evolution of the fibres positions

However, the data acquisition is done during all the process, enables us to analyse the behaviour of the fabric at any moment of the test, for each shape considered. Thus, figure 7 represents the evolution of the geometry shape at different stage of the stamping. This possibility can be used to determine when defaults appears in the reinforcement or for which process parameter they appear. 


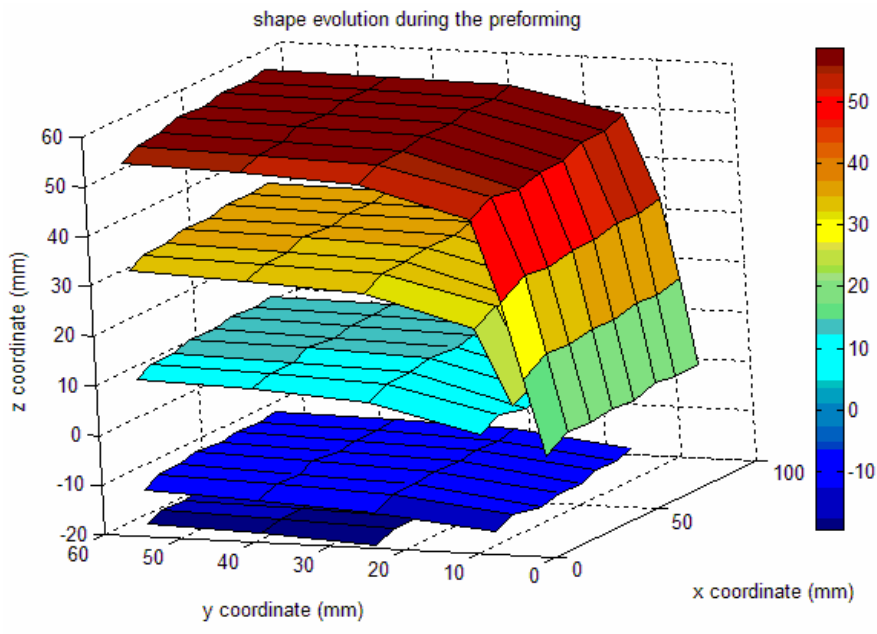

Fig.7 Shape evolution of an area of a square box preform during stamping

\section{CONCLUSIONS}

This study presented a tool for dry preforms stamping. This tool was developed in collaboration Tests were carried out successfully on different geometry preforms.

The post-processing made it possible to obtain the final shape of the preform but also the various intermediary shapes during the test. In addition, this tool also enables us to identify the local behaviour of the fibres.

Future works will be directed towards a basic constitution of experimental data and their correlation with numerical simulations results. In the other hand, parametric studies will be carried out on each preform in order to optimize the process parameters allowing obtaining preforms without defaults.

\section{REFERENCES}

1. Potter KD. History of the resin transfer moulding for aerospace applications. Composite Part A, 30, 1999;757-765.

2. Rudd CD, Long AC. Liquid molding technologies. Woodhead Publishing Limited; 1997

3. Maison S, Thibout C, Garrigues C, Garcin JL, Payen H, Sibois H, et al.. Technical developments in thermoplastic composites fuselages. SAMPE J 1998;34(5):33-9.

4. Zouari B., Daniel J.L., Boisse Ph, Awoven reinforcement forming simulation method. Influence of the shear stiffness, Computers \& Structures, 84, (2006) 351-363

5. Hamila N., Boisse Ph. Simulations of textile composite reinforcement draping using a new semi-discret three node finite element, Composite Part B, accepted, 2008.

6. Dumont F, Contribution a` l'expérimentation et à la modélisation du comportement mécanique de renforts de composites tissés, Ph.D. thesis, University Paris 6; 2003.

7. Dumont F, Hivet G, Rotinat R, Launay J, Boisse P, Vacher P. Identification des caractéristiques mécaniques de renforts tissés à partir de mesures de déformations par corrélation d'images. Mécaniques et Industrie 2003;4:627-35.

8. Boisse Ph., Zouari B., Daniel J.L., importance of in-plane rigidity in finite element analyses of woven fabric composite performing, Composite Part A, 37, (12) 2007;2201-2212

9. Launay J., Hivet G., Duong A.V., Boisse Ph., Experimental analysis of the influence of tensions on in plane shear behaviour of woven composite reinforcements, Composite Science and technology, 68, (2) 2008;506-515. 